\title{
STABILISASI TANAH LEMPUNG MENGGUNAKAN PASIR PANTAI TERHADAP NILAI CBR
}

\author{
Jeremi Sitinjak $^{1}$, Fatma Sarie ${ }^{2}$ dan Okrobianus Hendri ${ }^{3}$ \\ ${ }^{123}$ Program Studi Teknik Sipil, Fakultas Teknik, Universitas Palangka Raya \\ E-mail:jeremisitinjak1@gmail.com ${ }^{1}$, fatmasarie@jts.upr.ac.id ${ }^{2}$, \\ okrobianus@jts.upr.ac.id ${ }^{3}$
}

\begin{abstract}
ABSTRAK
Permasalahan yang sering dijumpai dalam pelaksanaan pembangunan konstruksi adalah tidak selalu ditemuinya tanah dasar (subgrade) yang memiliki nilai CBR atau daya dukung yang memadai, sehingga perlu dilakukan stabilisasi. Pada penelitian ini mengambil sampel tanah dari daerah Kasongan Lama, Katingan Hilir, Kabupaten Katingan, Kalimantan Tengah. Maksud dari penelitian ini adalah untuk menganalisa jenis tanah dan nilai CBR tanah dengan penambahan Pasir Pantai Ujung Pandaran sebagai bahan campuran. Tujuan dari penelitian ini adalah mengetahui seberapa besar pengaruh penambahan pasir pantai pada tanah lempung terhadap nilai CBR. Penelitian ini menggunakan metode eksperimen dan analisis data di laboratorium Mekanika Tanah, Fakultas Teknik Universitas Palangka Raya. Adapun penelitian yang dilakukan adalah 4 variasi yaitu 0\%, 5\%, $10 \%$ dan $15 \%$ dan pemeraman selama 3 hari. Setelah pengujian dan pengolahan data dilakukan didapat hasil sebagai berikut: $3,25 \% ; 4,05 \% ; 6,10 \%$; dan 7,30\%. Dari hasil nilai CBR dapat terlihat bahwa penambahan pasir pantai pada tanah lempung menunjukkan peningkatan nilai CBR pada tanah lempung sesuai dengan peningkatan persentase campuran.
\end{abstract}

Kata kunci: Tanah Lempung, Pasir Pantai, CBR, Tanah Dasar

\begin{abstract}
The problem that is often encountered in the implementation of construction development is that there is not always a subgrade that has an adequate CBR value or bearing capacity, so stabilization is necessary. In this study, soil samples were taken from the Kasongan Lama area, Katingan Hilir, Katingan Regency, Central Kalimantan. The purpose of this study was to analyze soil types and soil CBR values with the addition of Ujung Pandaran Beach Sand as a mixed material. The purpose of this study was to determine how much influence the addition of beach sand to clay soil had on the CBR value. This study uses experimental methods and data analysis in the Soil Mechanics laboratory, Faculty of Engineering, University of Palangka Raya. The research conducted was 3 variations, namely 0\%, 5\%, 10\% and 15\% and curing for 3 days. After testing and processing the data, the following results were obtained: $3.25 \%$; $4.05 \%$; $6.10 \%$; and $7.30 \%$. From the results of the CBR value, it can be seen that the addition of beach sand to clay soils shows an increase in CBR values in clay soils according to the increase in the percentage of the mixture.
\end{abstract}

Keywords: Clay, Beach Sand, CBR, Subgrade 


\section{PENDAHULUAN}

\section{Latar Belakang}

Menurut Hendarsin (2000), tanah dapat di definisikan sebagai sisa atau produk yang dibawa dari pelapukan batuan dalam proses geologi yang dapat ditembus dengan peralatan pengambilan contoh (sampling) pada saat pemboran dan dapat digali tanpa peledakan. Sampai pada saat ini tanah berguna sebagai bahan bangunan pada berbagai macam pekerjaan teknik sipil disamping itu tanah juga sebagai pendukung dari bangunan baik jalan maupun gedung. Ada berbagai jenis tanah yang masing-masing mempunyai karakteristik dan bentuk yang berbeda-beda, dari yang mempunyai daya dukung rendah sampai yang mempunyai daya dukung tinggi .

Permasalahan umum yang sering dijumpai dalam pelaksanaan pembangunan konstruksi jalan adalah tidak selalu ditemuinya tanah dasar (subgrade) yang memiliki daya dukung memadai, dalam menahan beban lalu lintas yang akan diterima (Rokky, Kamaluddin, \& Nuril 2017). Tanah sebagai lapisan subgrade yang dipakai bisa tanah timbun ataupun tanah asli. Dalam tanah timbun bahan yang sering dipakai adalah tanah lempung.

Salah satu parameter yang menjadi tolak ukur dalam penentuan kemampuan tanah dalam pembuatan sarana transportasi sebagai jalan yaitu nilai daya dukung tanah adalah berupa nilai California Bearing Ratio (CBR). Persyaratan nilai daya dukung tanah dikategorikan baik apabila nilai CBR berdasarkan pengujian lapangan sebesar $\geq 3 \%$ dan berdasarkan laboratorium diperoleh nilai $\geq 6 \%$.

Ada berbagai macam cara dalam meningkatkan daya dukung tanah lempung yaitu dengan cara pemadatan dan cara bahan pencampur/tambahan tanah. Dalam permasalahan ini, peneliti mengkaji dengan cara penambahan bahan stabilisasi menggunakan pasir. Alasan menggunakan pasir karena mudah ditemukan dalam tiap lokasi. Penambahan pasir sebagai bahan campuran diharapkan dapat meningkatkan stabilitas dan daya dukung tanah.

Berdasarkan latar belakang, pada pelaksanaan pembangunan kontruksi jalan harus diperhatikan dahulu subgrade-nya agar tidak terjadi kerusakan pada jalan. Oleh karena itu, peneliti tertarik untuk mengkaji lebih dalam tentang tanah lempung distabilisasi dengan pasir pantai. Selain itu karena pasir pantai masih sangat mudah ditemui agar dapat dipergunakan sebaik mungkin.

\section{Tujuan Penelitian}

Tujuan dari penelitian ini adalah mengetahui seberapa besar pengaruh penambahan pasir pantai pada tanah lempung terhadap nilai CBR. Penelitian ini menggunakan metode eksperimen dan analisis data di laboratorium Mekanika Tanah, Fakultas Teknik Universitas Palangka Raya.

\section{TINJAUAN PUSTAKA}

Tanah lempung merupakan agregat partikel-partikel berukuran mikroskopik dan submikroskopik yang berasal dari pembusukan kimiawi unsurunsur penyusun batuan, dan bersifat plastis dalam selang kadar air sedang sampai tinggi. Dalam keadaan kering sangat keras, dan tak mudah terkelupas hanya 
dengan jari tangan. Berdasarkan permasalahan tersebut, perlu adanya upaya untuk menambah kekuatan tanah lempung. Salah satu cara dengan melakukan stabilisasi untuk menanggulangi masalah-masalah yang terjadi pada tanah lempung. Pada penelitian ini dilakukan dengan memanfaatkan pasir pantai sebagai bahan tambah stabilisasi tanah lempung untuk mengetahui pengaruhnya terhadap nilai CBR.

Sistem klasifikasi tanah adalah sistem yang menjelaskan secara singkat sifat-sifat umum tanah yang bervariasi kedalam bentuk tabel dan grafik. Sistem klasifikasi yang digunakan dalam penelitian ini adalah sistem klasifikasi AASHTO(American Association of State Highway and Transportation Official) dan sistem klasifikasi USCS(Unified Soil Classification System).

Pasir adalah partikel batuan yang berukuran $0,074 \mathrm{~mm}$ sampai dengan 5 $\mathrm{mm}$ berkisar dari kasar (3 mm sampai $5 \mathrm{~mm}$ ) dan halus $(<1 \mathrm{~mm})$ (Joseph E. Bowles, 1984). Pasir dapat dibagi lagi menjadi fraksi-fraksi kasar, medium, dan halus. Pasir dapat dideskripsikan sebagai yang bergradasi baik, bergradasi buruk,bergradasi seragam atau bergradasi timpang (gap graded) (R.F.Craig dan Budi Susilo S, 1987). Pasir pantai merupakan bahan bangunan yang relatif murah dan sangat mudah ditemui, sehingga masih dapat dimanfaatkan.

CBR adalah suatu perbandingan antara beban percobaan (test load) dengan beban standard dan dinyatakan dalam persen. Istilah CBR menunjukkan suatu perbandingan (ratio) antara beban yang diperlukan untuk menekan piston logam (luas penampang 3 sqinch) ke dalam tanah untuk mencapai penurunan (penetrasi) tertentu dengan beban yang diperlukan pada penekanan piston terhadap material batu pecah di California pada penetrasi yang sama (Canonica, 1991). Harga CBR adalah nilai yang menyatakan kualitas tanah dasar dibandingkan dengan bahan standar berupa batu pecah yang mempunyai nilai CBR sebesar $100 \%$ dalam memikul beban. Sedangkan, nilai CBR yang didapat akan digunakan untuk menentukan tebal lapisan perkerasan yang diperlukan di atas lapisan yang mempunyai nilai CBR tertentu.

Tabel 1. Klasifikasi Nilai CBR Tanah

\begin{tabular}{ccc}
\hline CBR $(\%)$ & Tingkatan Umum & Kegunaan \\
\hline $0-3$ & Very poor & Subgrade \\
$3-7$ & Poor to fair & Subgrade \\
$7-20$ & Fair & Subbase \\
$20-50$ & Good & Base or subbase \\
$>50$ & Excellent & Base \\
\hline
\end{tabular}

\section{METODE}

Penelitian ini menggunakan metode uji laboratorium dan eksperimen untuk mendapatkan data. Data tersebut dianalisis untuk mendapatkan suatu hasil perbandingan dengan syarat-syarat yang ada. Ada 2 pemeriksaan yaitu sifat fisik tanah asli dan pemeriksaan sifat mekanik tanah sebelum dan sesudah di lakukan penambahan pasir pantai dan pemeraman selama 3 hari. Penelitian ini dilaksanakan di Laboratorium Mekanika Tanah, Fakultas Teknik Universitas Palangka Raya. 
Memulai penelitian, setelah itu peninjauan penelitian terdahulu, mempersiapkan sampel untuk ujilabolatorium, kemudian melakukan tahap pengujian meliputi sifat fisik dan mekanik, pada saat melakukan pengujian sifat fisik sampel yang digunakan adalah sampel tidak terganggu. Sedangkan, pada pemeriksaan sifat mekanik yaitu uji pemadatan dan CBR dapat menggunakan sampel terganggu tetapi, kadar air yang ada pada sampel harus dihilangkan terlebih dahulu. Setelah semua pengujian selesai dan data sudah didapatkan selanjutnya menganalisis, menyimpulkan penelitian, dan selesai, seperti pada gambar

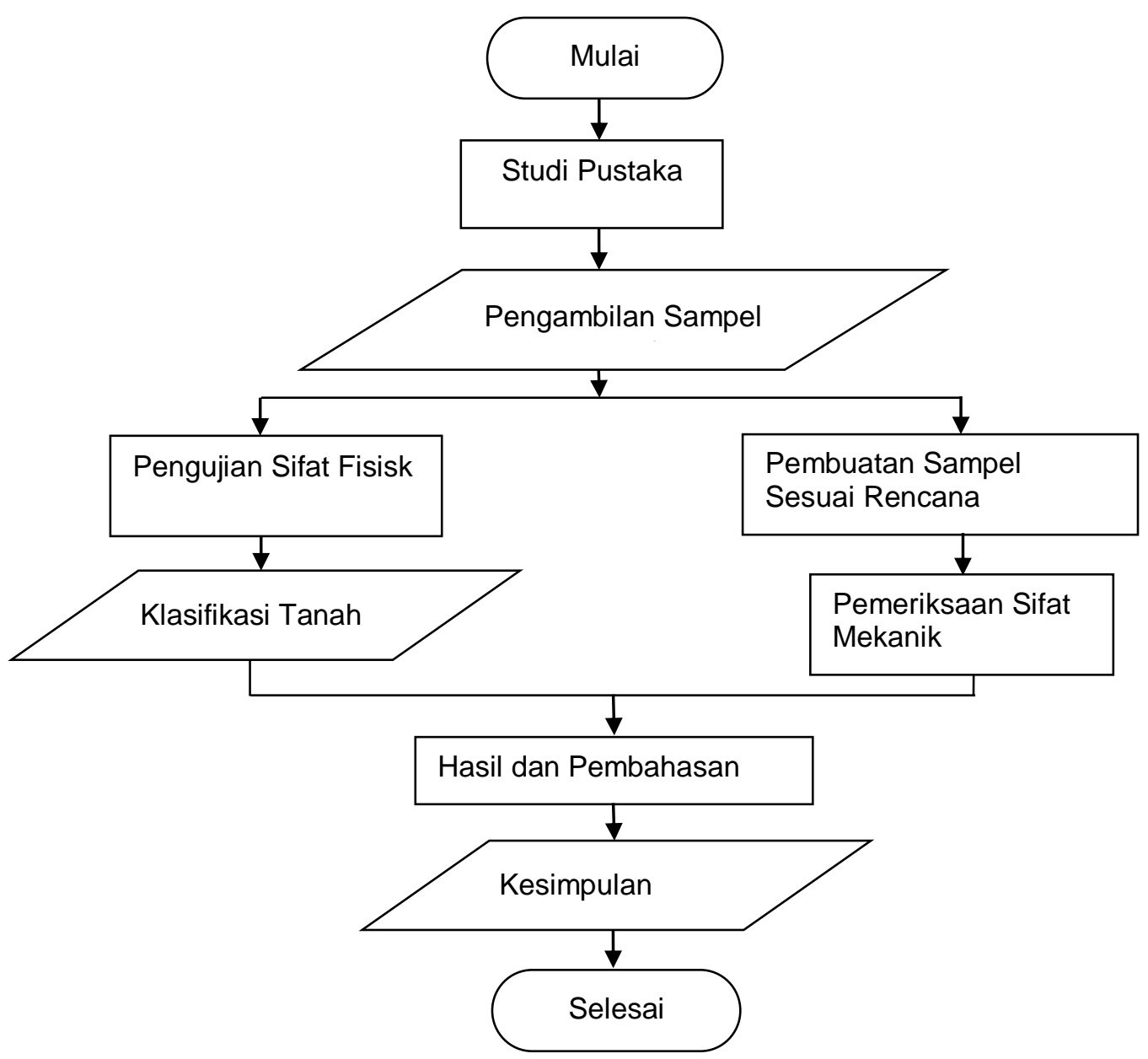

Gambar 1. Flow Chart Diagram Alur Pelaksanaan Penelitian

\section{HASIL DAN PEMBAHASAN}

\section{Hasil}

Pengujian sifat fisik yang dilakukan pada penelitian ini adalah uji analisa saringan dan batas-batas aterberg. Hasil dari pengujian dapat dilihat dalam tabel maupun grafik pada halaman berikutnya. 
Tabel 2. Hasil Uji Analisa Saringan

Banyak sampel: 1000gr

\begin{tabular}{cccccc}
\hline $\begin{array}{c}\text { No. } \\
\text { Saringan }\end{array}$ & Uk. Saringan & $\begin{array}{c}\text { B. } \\
\text { Tertahan } \\
(\mathrm{gr})\end{array}$ & $\begin{array}{c}\Sigma \mathrm{B} . \\
\text { Tertahan } \\
(\mathrm{gr})\end{array}$ & $\begin{array}{c}\text { Persentase } \\
\text { B. Tertahan } \\
\%\end{array}$ & Lolos\% \\
\hline No. 4 & 4,78 & 0,00 & 0,00 & 0,00 & 100,00 \\
No. 8 & 2,38 & 1,10 & 1,10 & 0,11 & 99,89 \\
No. 10 & 2 & 1,86 & 2,96 & 0,30 & 99,70 \\
No. 50 & 0,3 & 22,52 & 126,77 & 12,68 & 87,32 \\
No. 100 & 0,149 & 111,21 & 343,03 & 34,30 & 65,70 \\
No. 200 & 0,074 & 142,57 & 485,60 & 48,56 & 51,44 \\
Pan & - & 514,34 & 999,94 & 99,99 & 0,01 \\
\hline
\end{tabular}

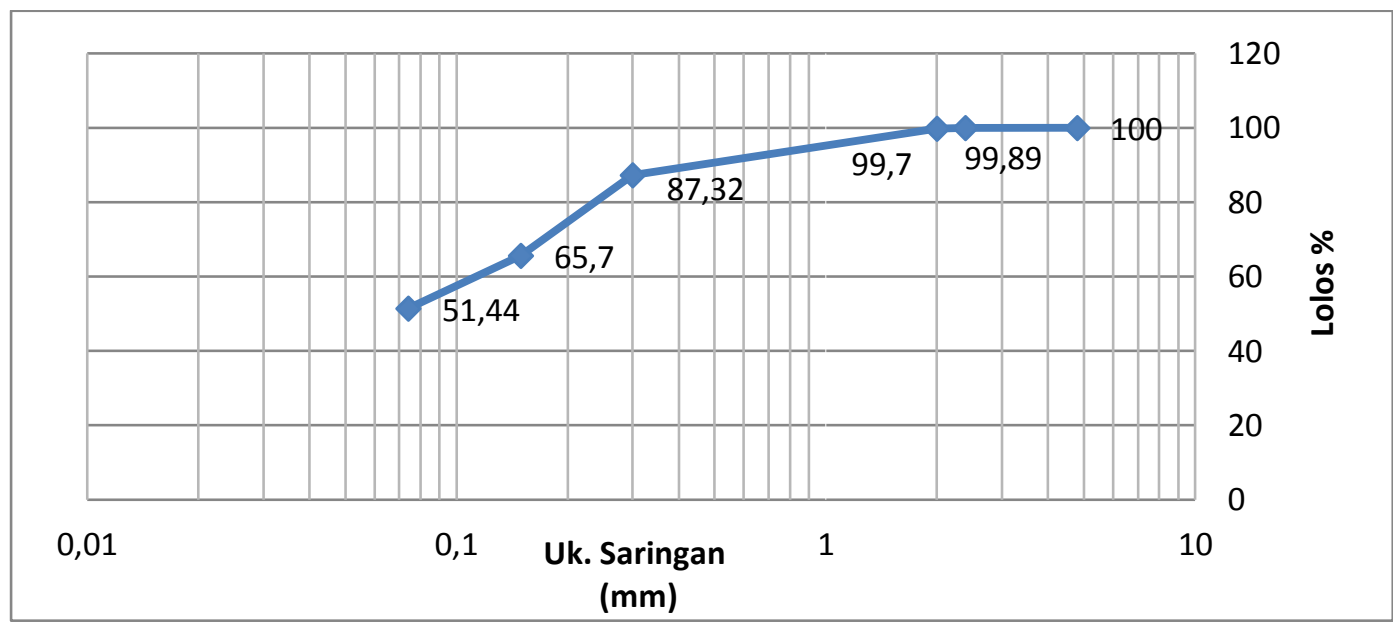

Gambar 2. Grafik Hasil Ujji Analisis Hidrometer

Hasil dari pengujian batas-batas atterberg dapat dilihat pada tabel dan grafik berikut.

Tabel 3. Hasil Uji Batas Cair

\begin{tabular}{lccccccc}
\hline \multicolumn{1}{c}{ Nomor Cawan } & \multicolumn{9}{c}{ Pukulan } \\
& \multicolumn{2}{c}{$10-20$} & \multicolumn{2}{c}{$20-30$} & \multicolumn{2}{c}{$30-40$} \\
& A & B & A & B & A & B \\
\hline Bayak Pukulan & \multicolumn{2}{c}{16} & \multicolumn{2}{c}{28} & \multicolumn{2}{c}{32} \\
Berat Cawan (gr) & 9,42 & 14,34 & 14,87 & 9,81 & 14,23 & 13,83 \\
Berat cawan + Tanah basah (gr) & 42,04 & 48,82 & 47,47 & 41,69 & 47,61 & 48,56 \\
Berat cawan + Tanah kering (gr) & 28,85 & 34,98 & 36,59 & 31,11 & 37,75 & 38,54 \\
Berat air (gr) & 13,19 & 13,84 & 10,88 & 10,58 & 9,86 & 10,02 \\
Berat tanah kering (gr) & 19,43 & 20,64 & 21,72 & 21,3 & 23,52 & 24,71 \\
Kadar air (\%) & 67,88 & 67,05 & 50,09 & 49,67 & 41,92 & 40,55 \\
Kadar air Rata-Rata (\%) & \multicolumn{2}{c}{67,47} & & 49,88 & & 41,24 \\
\hline
\end{tabular}


Dari data pada tabel kemudian diplotkan kedalam grafik batas cair hingga didapatkan hasil batas cair.

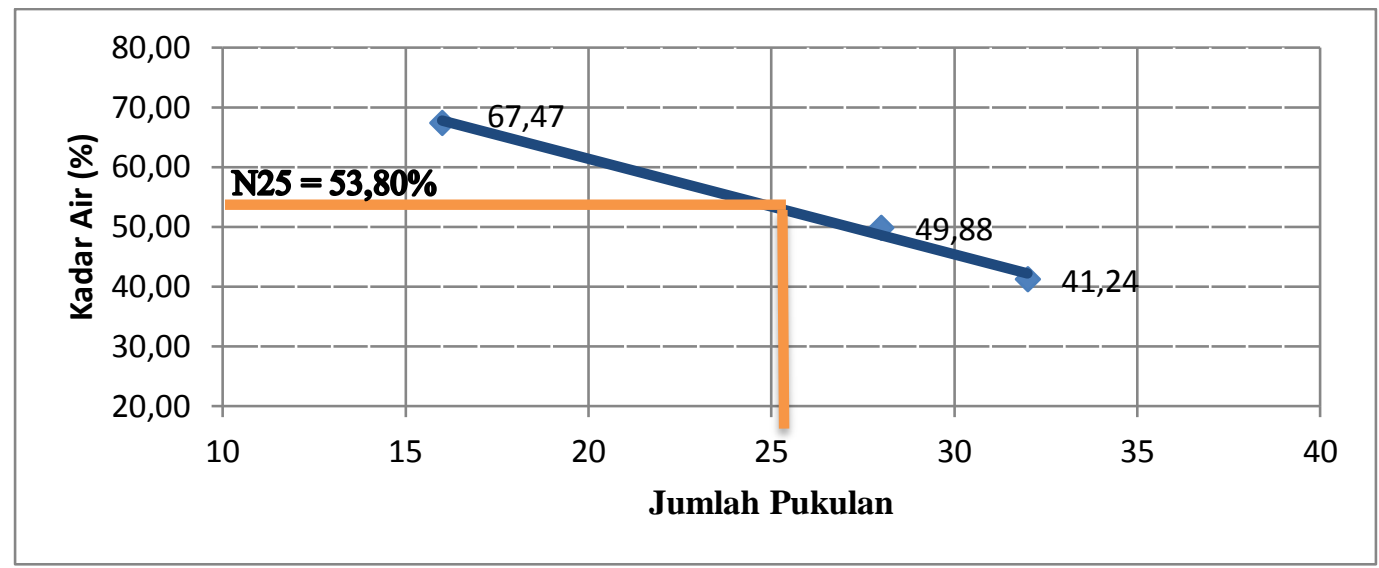

Gambar 3. Grafik Hasil Ujji Batas Cair

Batas cair (LL) dari penelitian ini adalah 53,80\%

Tabel 4. Hasil Uji Batas Plastis

Batas Plastis (PL)

Nomor Cawan

I II

\begin{tabular}{lcc}
\hline Berat Cawan (gr) & 10,29 & 10,17 \\
Berat cawan + Tanah basah (gr) & 12,69 & 13,11 \\
Berat cawan + Tanah kering (gr) & 12,14 & 12,43 \\
Berat air (gr) & 0,55 & 0,68 \\
Berat tanah kering (gr) & 1,85 & 2,26 \\
Kadar air (\%) & 29,73 & 30,09 \\
Kadar air Rata-Rata (\%) & \multicolumn{2}{c}{29,91} \\
\hline
\end{tabular}

Didapat Batas Plastis (PL) sebesar 29,91\%

Sehingga didapat Indeks Plastis (IP) $=$ LL-PL

$$
=53,80-29,91=23,89 \%
$$

Pemadatan yang dilakukan adalah pemadatan tanah asli dan pemadatan tanah asli dengan campuran penambahan pasir pantai. Parameter yang diperoleh dari pengujian menggunakan standar proctor adalah nilai kepadatan kering mkasimum (Maximum Dry Density/Ydry) dan kadar air optimum (Optimum moisture Content/OMC). Penambahan air dilakukan dengan cara coba-coba atau eksperimen. Adapun hasil pengujian yang dipaparkan adalah sampel tanah lempung tanpa campuran (tanah asli) dengan pemeraman 3 hari sebagai berikut. 
JURNAL KACAPURI

JURNAL KEILMUAN TEKNIK SIPIL

Volume 4 Nomor 2 Edisi Desember 2021

Tabel 5. Hasil Pengujian Kepadatan Tanah Asli

\begin{tabular}{cccc}
\hline Sampel & $\begin{array}{c}\text { Penambahan } \\
\text { Air }(\mathrm{cc})\end{array}$ & $\begin{array}{l}\text { Berat Isi } \\
\text { Kering } \\
(\mathrm{gr} / \mathrm{cc})\end{array}$ & $\begin{array}{c}\text { Kadar Air } \\
(\%)\end{array}$ \\
\hline 1 & 450 & 1,367 & 19,71 \\
2 & 500 & 1,369 & 21,85 \\
3 & 550 & 1,381 & 23,11 \\
4 & 600 & 1,376 & 25,53 \\
5 & 650 & 1,373 & 27,07 \\
\hline
\end{tabular}

Hasil pengujian pemadatan tanah asli pada tabel 5 kemudian diplot kedalam grafik hubungan antar kadar air dengan berat isi kering seperti pada gambar 4 berikut ini.

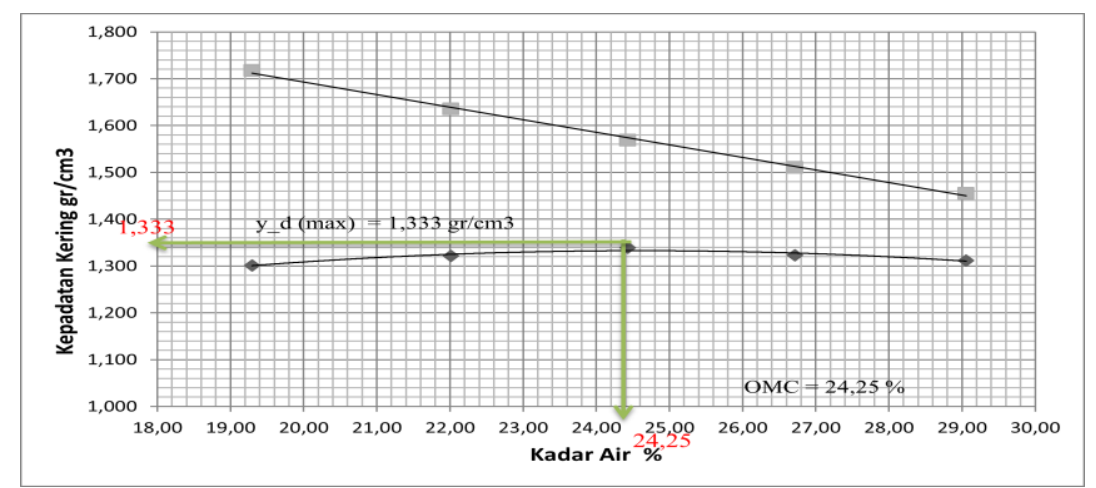

Gambar 4. Grafik Hubungan Kadar Air dan Berat Isi Kering Tanah

Berdasarkan grafik hubungan antara kadar air dengan berat isi kering tanah sehingga didapat nilai berat isi kering maksimum $1,333 \mathrm{gr} / \mathrm{cm}^{3}$ dan nilai kadar air optimum 24,25\%. Adapun hasil pengujian kepadatan tanah asli dan campuran pasir pantai sebagai berikut :

Tabel 6. Hasil Pengujian Kepadatan Tanah Asli

\begin{tabular}{ccc}
\hline Variasi Campuran & $\begin{array}{c}\text { Kadar Air } \\
(\%)\end{array}$ & $\begin{array}{l}\text { Berat Isi } \\
\text { Kering } \\
\text { (gr/cc) }\end{array}$ \\
\hline Tanah Asli & 24,40 & 1,38 \\
Tanah Asli + 5\% pasir pantai & 24,80 & 1,43 \\
Tanah Asli + 10\% pasir pantai & 25,20 & 1,45 \\
Tanah Asli + 15\% pasir pantai & 26,60 & 1,50 \\
\hline
\end{tabular}

Hasill dari tabel 5 yaitu kadar air optimum dan berat isi kering maksimum akan menjadi acuan dalam pengujian dan perhitungan nilai CBR. Sesuai dengan campuran dan kadar air masing-masing pengujian. Pengujian CBR dimaksudkan untuk mengetahui seberapa besar pengaruh penambahan pasir pantai terhadap tanah lempung. 
Tabel 7. Hasil Pengujian Penetrasi Laboratorium

\begin{tabular}{ccccc}
\hline $\begin{array}{c}\text { Dial Reading } \\
(\mathrm{mm})\end{array}$ & $\begin{array}{c}\text { Penurunan } \\
\text { (inch) }\end{array}$ & 10x Pukulan & $\begin{array}{c}\text { Beban }(\mathrm{lbs}) \\
\text { 25x Pukulan }\end{array}$ & 56x Pukulan \\
\hline 0,00 & 0,00 & 0,00 & 0,00 & 0,00 \\
0,25 & 0,01 & 1,61 & 6,44 & 22,53 \\
0,50 & 0,02 & 12,87 & 20,28 & 33,79 \\
1,00 & 0,04 & 31,54 & 43,45 & 51,50 \\
1,50 & 0,06 & 42,81 & 57,93 & 70,81 \\
2,00 & 0,08 & 48,60 & 75,31 & 86,90 \\
2,50 & 0,10 & 72,42 & 93,02 & 107,50 \\
3,00 & 0,12 & 82,07 & 111,04 & 120,70 \\
4,00 & 0,16 & 90,12 & 125,20 & 135,82 \\
5,00 & 0,20 & 99,78 & 138,40 & 167,36 \\
6,00 & 0,24 & 111,04 & 163,50 & 177,02 \\
8,00 & 0,32 & 112,65 & 183,46 & 208,24 \\
\hline
\end{tabular}

Dari tabel hasi pengujian penetrasi diplotkan kedalam grafik hubungan beban dengan penurunan dapat dilihat dari grafik 5 .

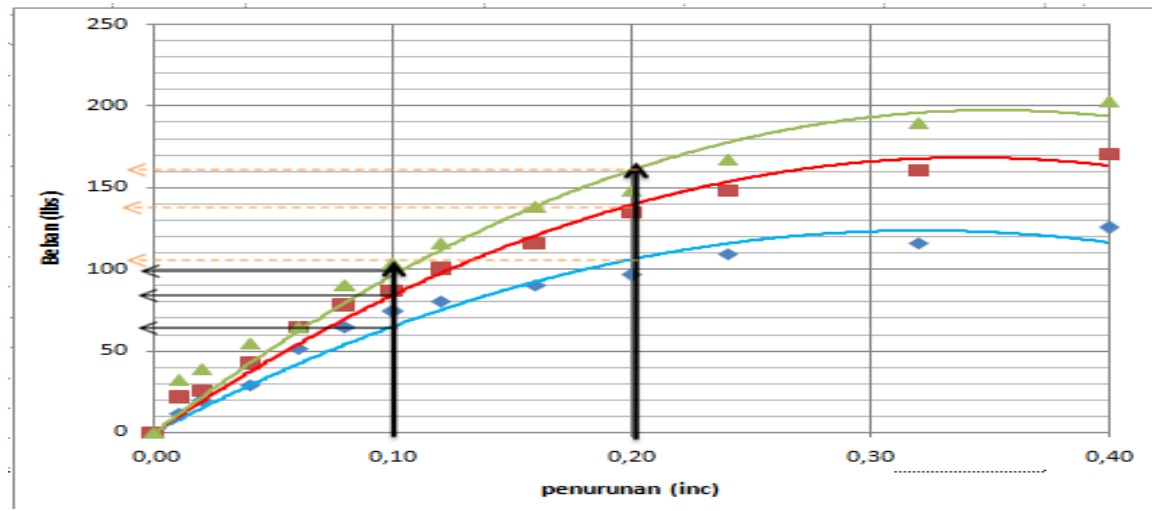

Gambar 5. Grafik Hubungan Beban dan Penurunan

Penentuan nilai CBR yang digunakan untuk menghitung kekuatan tanah pada penetrasi 0,1 " dan 0,2 " adalah

Nilai CBR pada penetrasi $0,1 "=\frac{\text { nilai beban }}{3 \times 1000} \times 100 \%$

Nilai CBR pada penetrasi $0,2 "=\frac{\text { nilai beban }}{3 \times 1500} \times 100 \%$

Tabel 8. Hasil Perhitungan Nilai CBR tanah Asli

\begin{tabular}{|c|c|c|c|}
\hline Pukulan & $10 x$ & $25 x$ & $56 x$ \\
\hline penurunan 0,10 & $74 / 3000 \times 100=2,46$ & $90 / 3000 \times 100=3,00$ & $101 / 3000 \times 100=3,36$ \\
\hline penurunan 0,20 & $120 / 4500 \times 100=2,66$ & & $\begin{array}{c}172 / 4500 \times 100= \\
3,82\end{array}$ \\
\hline
\end{tabular}



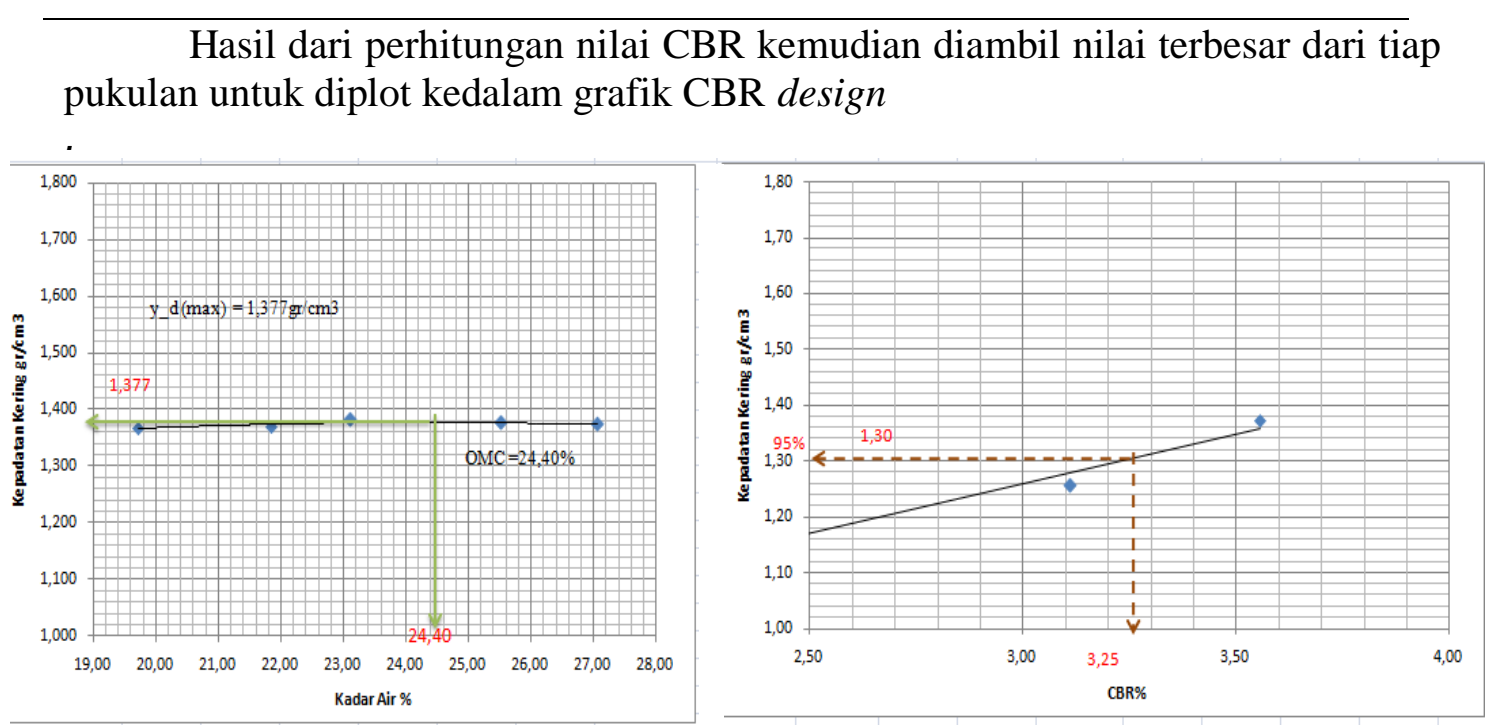

Gambar 6. Grafik CBR Design

Dari grafik hubungan tersebut didapat cbr sebesar 3,25\%, adapun hasil Nilai CBR setiap campuran dapat dilihat pada tabel 8.

Tabel 9. Hasil Perhitungan Nilai CBR tanah Asli

\begin{tabular}{ccc}
\hline Variasi Campuran & $\begin{array}{c}\text { Berat Isi Kering } \\
\left(\mathrm{gr} / \mathrm{cm}^{3}\right)\end{array}$ & $\begin{array}{c}\text { Nilai CBR } \\
(\%)\end{array}$ \\
\hline Tanah Asli + Campuran Kerikil 0\% & 1,30 & 3,25 \\
Tanah Asli + Campuran Kerikil 5\% & 1,34 & 4,05 \\
Tanah Asli + Campuran Kerikil 10\% & 1,38 & 6,10 \\
Tanah Asli + Campuran Kerikil 15\% & 1,42 & 7,30 \\
\hline
\end{tabular}

\section{Pembahasan}

Berdasarkan hasil dari pengujian sifat fisik tanah dapat diklasifikasikan menurut klasifikasi USCS maupun klasifikasi AASTHO. Klasifikasi tanah berdasarkan sistem USCS mengikuti prosedur sebagai berikut:

1. Dari hasil pemeriksaan analisis saringan, persentase material lolos saringan No.200 $(0,075 \mathrm{~mm})$ rata-rata $=51,43 \%>50 \%$, maka tanah tersebut termasuk tanah berbutir halus.

2. Dari hasil pemeriksaan batas-batas atterberg, didapat nilai batas cair (LL) rata-rata $=53,80 \%<50 \%$, maka tanah tersebut termasuk kelompok $\mathrm{CH}$.

3. Dari hasil pemeriksaan batas-batas atterberg, didapat nilai batas plastis (PL) rata-rata $=29,91 \%$, jadi dapat dihitung nilai indeks plastisitas PI $=$ LL - PL $=53,80 \%-29,91 \%=23,89 \%$.

4. Dari grafik batas cair (LL) dan indeks plastisitas (PI) yang diplot maka 
tanah tersebut termasuk kelompok Lempung anorganik dengan plastisitas tinggi, lempung "gemuk" (fat clay) $(\mathrm{CH})$ seperti pada gambar 7 .

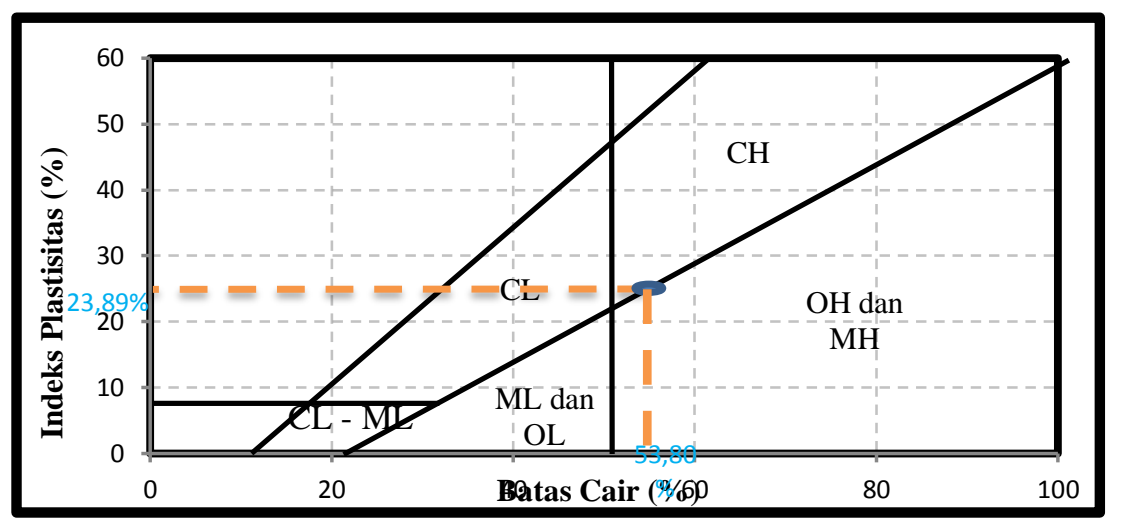

Gambar 7. Klasifikasi Tanah Berdasarkan Sistem Klasifikasi USCS

Klasifikasi tanah berdasarkan sistem AASHTO mengikuti prosedur sebagai berikut:

1. Dari hasil pemeriksaan analisis saringan, persentase material lolos saringan No. $200(0,075 \mathrm{~mm})$ adalah $51,43 \%>35 \%$, maka tanah tersebut termasuk dalam klasifikasi lanau-lempung, kelompok A-4, A-5, A-6 atau A-7.

2. Pemeriksaan batas-batas Atterberg didapat nilai batas cair (LL) rata-rata $=$ $53,80 \%<40 \%$ dan indeks plastisitas $(\mathrm{PI})$ rata-rata $=23,89 \%>11 \%$ maka tanah tersebut termasuk kelompok sub grup A-7-6

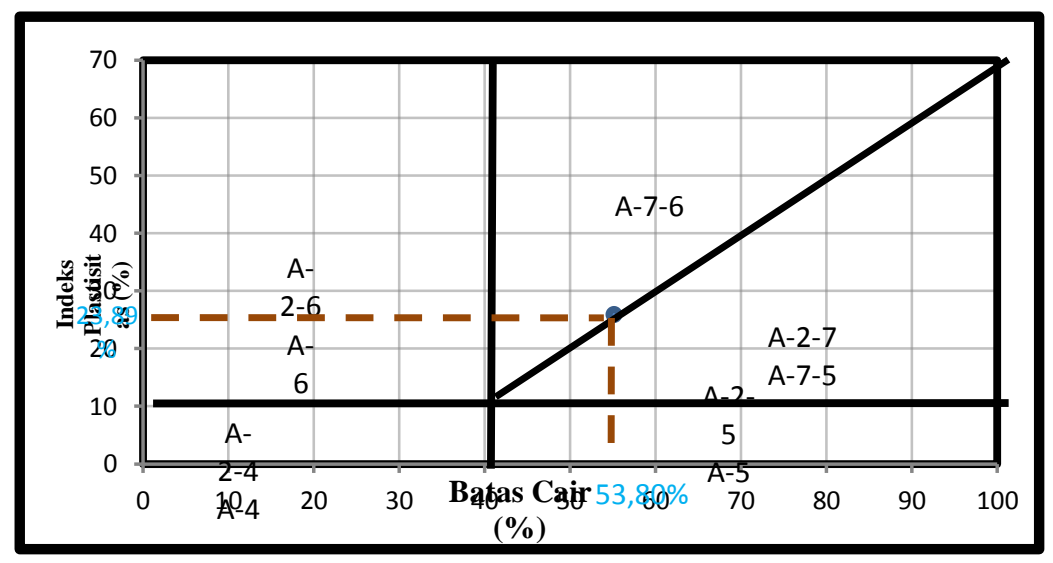

Gambar 8. Klasifikasi Tanah Berdasarkan Sistem Klasifikasi AASHTO

Sistem klasifikasi ini membagi tanah dalam beberapa kelompok yang setiap kelompoknya dievaluasi terhadap indeks kelompoknya (GI).

$$
\begin{array}{ll}
\text { GI } & =((\mathrm{F}-35)[0,2+0,005(\mathrm{LL}-40)]+(0,001(\mathrm{~F}-15)(\mathrm{PI}-10)) \\
\mathrm{GI} & =((51,43-35)[0,2+0,005(53,80-40)]+(0,001(51,43-15)(23,89-10))= \\
& 12,73 \sim 13
\end{array}
$$

Jadi, berdasarkan klasifikasi AASTHO tanah yang berasal dari Kasongan Lama, Katingan Hilir, Kabupaten Katingan, Kalimantan Tengah, diklasifikasikan sebagai tanah berlempung dalam kelompok A-7-6 (13). 
Berdasarkan hasil pengujian sifat mekanik, bahwa nilai CBR tanah asli Kasongan Lama, Katingan Hilir, Kabupaten Katingan, Kalimantan Tengah cukup rendah 3,25\%. Sedangkan setelah distabilisasi dengan pasir pantai dengan campuran 5\%; 10\%; dan $15 \%$ meningkat menjadi 4,05\%; 6,10\%; dan 7,30\% dimana seiring penambahan persentase campuran terjadi kenaikan nilai CBR.

\section{Kesimpulan}

Berdasarkan hasil uji lab yang dilakukan, diperoleh hasil nilai CBR tertinggi adalah 7,30\% yang dimana nilai CBR naik $125 \%$ dari nilai CBR tanah asli. Menurut Klasifikasi Nilai CBR Tanah yang ada pada tabel 1 maka tanah yang telah distabilisai menggunkan pasir pantai sebanyak $15 \%$ dengan pemeraman 3 hari dapat digunakan sebagai subgrade maupun subbase.

\section{Saran}

Perlu dilakukan pemambahan variasi pemeraman agar ada sebagai pembanding pengaruh pemeraman dan pada penelitian selanjutnya diharapkan melakukan pemeriksaan sifat fisik bahan campuran.

\section{Daftar Pustaka}

American Society for Testing and Materials (ASTM) D 1883-73. 2002. Standard Test Method for CBR (California Bearing Ratio) of LaboratoryCompacted Soils.

ASTM Internasional. 2002. Standard test methods for specific gravity of soil solids by water pycnometer(ASTM D-854), Annual Books of ASTM Standards, USA.

ASTM International. 2005. Standard Test Method for Liquid Limit, Plastic Limit, and Plasticity Index Soils (ASTM D 4318), United State : ASTM International

Bowles, J.E. 1984. Sifat-sifat Fisis dan Geoteknis Tanah. Jakarta: Erlangga.

Craig, R.F dan Susilo S. Budi. 1987. Mekanika Tanah. Jakarta: Erlangga.

Hendarsin. 2000. Perencanaan Teknik Jalan Raya. Bandung: Politeknik Negeri Bandung.

Simanjuntak, M.R., Lubis, K., dan Rangkuti, N.M. (2017) Stabilisasi Tanah Lempung Dengan Campuran Pasir Pantai terhadap Nilai CBR. Journal of Civil Enggineering, Building and Transportation, 1(2): 96-104 